\title{
Integrating climate change adaptation and human development: a commentary
}

\author{
John Lemons* \\ Department of Environmental Studies, University of New England, Biddeford, Maine 04005, USA
}

\begin{abstract}
I discuss why integration of global climate change and human development aid programs requires consideration of some understudied uncertainties in making projections of future climate and environmental conditions at local and regional scales, and further, the value-laden policy consequences of dealing with uncertainties for national and international development programs. Additionally, I propose that conflicts between the interests of humans and other species be given greater attention than has been done by those involved in human development aid.
\end{abstract}

KEY WORDS: Climate change adaptation · Human development aid $\cdot$ Scientific uncertainties

\section{INTRODUCTION}

The communities of people working on global climate change and human development aid programs have, for the most part, worked separately in trying to achieve their respective goals. Generally speaking, the global climate change community has focused on mitigation and adaptation to climate change, and the human development aid community has focused on alleviation of human poverty regardless of the causes (Brown 2010). In addition, the global climate change community has considered non-human species in its promulgation of mitigation and adaptation policies, whereas the human development community has taken a more anthropogenic view.

Increasingly, there is recognition that the global climate change and the human development communities need to work more closely together, if for no other reason than that global climate change can affect the capacity of human development prospects and climate change policies should take into account human development needs. For example, recommendations have been made to simultaneously combat human poverty and better enable the world's poor and vulnerable to protect themselves against climate change by acquir- ing more adequate information in terms of the situation of the poor, developing infrastructure, ensuring social protection, and using adaptation funds for climate change protection (WB 2009). Further, many global climate change studies conclude that a significant percentage of the world's non-human species are at risk of extinction from such change, and heretofore this risk is something that has been understudied or undervalued by the human development communities. Increasingly, new information on the rate of global climate change and its impacts suggest an unprecedented urgency to implement effective mitigation and adaptation strategies (Allison et al. 2009).

In order for the 2 communities to work more closely together and achieve practical results that alleviate impacts both from global climate change and poverty, there must be adequate information to guide decisionmakers at local and regional levels because it is at these levels that programs must be implemented to be most efficacious given the urgency of dealing with impending impacts. As I discuss, local and regional information is often understudied and not available for most places in the developing world. For example, national adaptation programmes of action (NAPA) under the United Nations Framework Convention in 
Climate Change (UNFCCC) almost exclusively focus efforts to mitigate local vulnerability of populations and ecosystems on near-term rather than long-term planning and almost always use global general circulation models (GCMs) as a basis for informing mitigation and adaptation programmes despite the lack of GCMs' local and regional details and lack of predictive capabilities (see current NAPA programmes at http://unfccc.int/cooperation_support/least_developed_ countries_portal/submitted_napas/items/4585.php). A recent United Nations Development Programme report (UNDP 2007) discusses needs to integrate and address climate change and poverty, but does not delve into the question of whether adequate information and resources exist to implement actions on local and regional levels other than acquiring newer and more complete information. Likewise, human development programmes generally focus on solving nearterm problems to alleviate poverty and typically do not take into account local and regional climate change information because often it is not available and because the programmes generally attempt to deal with near-term alleviation of poverty regardless of the cause. Interestingly, Michaelowa \& Michaelowa (2010) report that over 11500 randomly selected human development aid projects overstated or were erroneous in coding projects as climate-change relevant and, accordingly, also did not address issues about scientific uncertainty of local and regional climate change impacts. Tschakert (2007) argues that pro-poor human development aid agendas should include climate change as an opportunity to build livelihood resilience out of poverty, including the ability for people to recover, learn, adapt, and anticipate through community empowerment. In particular, she emphasizes the need to provide options to alleviate poverty and adapt to climate change without the need to identify specific climate events for particular places.

At the same time, there is recognition that countries promulgating climate change adaptation policies as well as human development aid programs need to base long-term planning on information about which there is a higher degree of scientific confidence compared to, say, GCMs (Kueppers et al. 2005, Pierce et al. 2009). This recognition seems overdue because scientific uncertainty and global climate change have been discussed by the Intergovernmental Panel on Climate Change (IPCC) as well as by others despite the relative absence of discussion in the UNFCCC adaptation and human development aid literature.

Increasingly, there is the view that local and regional models of climate change (RCMs) might have promise for providing greater detail for local and regional climate change impacts. If adequate RCMs are not available, then this raises value-laden questions about how and on what basis uncertainties about local and regional impacts of global climate change should be assessed and, hence, how both adaptation and human development aid funds should be allocated.

The purpose of this commentary is twofold: First, to describe some of the uncertainty in making local and regional projections of future climate change and its impacts and to identify some value-laden questions that flow from uncertainty in the context of climate change adaptation and human development. The example I use for my discussion of uncertainty concerns the status of local and regional RCMs. Second, to identify some of the ethical dilemmas that confront climate change adaptation and development that stem from projections that 20 to $30 \%$ of all species could become extinct from global climate change (IPCC 2007). Overall, the purpose of the commentary is not to provide a definitive or exhaustive treatment of the topics but rather to serve as a 'conversation starter' to promote greater discussion of issues that heretofore have been under-discussed in the global climate change adaptation and human development aid literature.

\section{UNCERTAINTIES FROM LOCAL AND REGIONAL CLIMATE MODELS AND IMPLICATIONS FOR ADAPTATION AND DEVELOPMENT}

Because there is a dearth of information concerning local and regional impacts of global climate change, governmental and non-governmental decision-makers still primarily rely on GCMs to develop adaptation plans under UNFCCC's adaptation fund and human development programs that use climate information for promulgation of aid programs.

GCMs are used to project large-scale aspects of the climate but are not yet capable of providing accurate detailed description of local and regional climate change or impacts that are often needed to make decisions about climate change adaptation or development aid policies and programs (e.g. agricultural programs, enhanced water resources, mitigation of soil degradation, conservation of species, and human health programs). Generally speaking, the spatial resolution of GCMs can be on the order of 100 to $300 \mathrm{~km}^{2}$, while local or regional models can be on the order of 10 to $50 \mathrm{~km}^{2}$. Compared to GCMs, RCMs provide more detailed information because of their higher resolution. However, despite the increase of resolution and information in RCMs, significant discrepancies exist between them and observational ground-level data. Further, it is difficult to compare data between GCMs and RCMs because significant differences in projections exist between the 2 types of models (Kueppers et al. 2005). 
A lot of scientific work and resources are devoted to developing refined RCMs that increase resolution and comport more highly with observational data and have greater capabilities to project future conditions. However, from the standpoint of integrating climate change and human development aid, several things need to be noted: (1) local physical and biotic information are required as inputs for accurate RCMs; (2) at the current state of RCM development, there is no guarantee that past relationships will hold in the future; (3) data input for RCMs is intensive and sufficient data for most places in developing nations, where climate change adaptation and development aid are most needed, are lacking; and (4) RCMs require sophisticated and powerful computers and these too are lacking in developing compared to developed nations (Pierce et al. 2009). These kinds of constraints create uncertainties that make it difficult to project future conditions of local and regional factors, such as temperature, rates of temperature increase, frequency and magnitude of intense storms, precipitation patterns, impacts on biota, which crops are best suited for particular geographical areas, and incidence and spread of diseases, to name a few. The uncertainties create huge financial risks because handling them literally involves billions of dollars for specific projects and infrastructure and, obviously, whether this money is spent as climate change adaptation funds or as human development aid funds, the efficacious use of funds seems to require that funded programs be designed to address sufficiently the problems of local and regional changing climates. Obviously, there is great need for both the climate change adaptation and human development aid communities to meet informational needs (Giorgi \& Jones 2009).

One value-laden dilemma stems from the situation that the quantity and quality of local and regional information relevant to climate change adaptation and development aid in developing nations can vary greatly by nation simply because of historical and current differences in scientific capacities (UNESCO 2000). For example, countries such as Niger, Mongolia or Somalia do not possess the scientific capabilities or proportionate climate change funding available to those such as Brazil, Egypt, Mexico, or India.

Given this situation, countries of the latter category could have an advantage for projects that support implementation of climate change adaptation or development aid projects compared to countries that still need to acquire significant amounts of baseline data. While a dearth of local and regional scientific knowledge exists in many developing countries, there is also an understanding from some that governments and businesses are faced with making decisions now despite the uncertainties (WCRP 2009). On the other hand, others indicate that both climate change adaptation and human development aid require more certain information about current and projected climate and relevant resource conditions prior to approval for project funding (Kueppers et al. 2004). Given finite resources for climate change adaptation and human development aid, should greater assistance for implementation of adaptation or human development aid projects be given to countries or local and regional areas of countries where more certain information exists? If not, what should the informational requirements be for providing assistance under conditions of uncertainty and given the disparity of scientific capabilities between nations? This is not a moot question because, although the NAPAs (required to be submitted to the UNFCCC's adaptation fund) require each country to assess and identify social and environmental resources vulnerable to climate change, there are no agreed upon scientific methods or methodological requirements for such assessments, and uncertainties in the assessments are not discussed or quantified in any explicit or transparent manner.

A second kind of dilemma might be shown by the following example. Suppose that in a particular country empirical data for a local area indicate with 'adequate' certainty that saltwater due to rising sea levels is intruding on freshwater resources in some areas. At the same time, suppose that in agricultural regions within the country there are indications that climate change might adversely impact agricultural productivity and that, depending on future conditions of, say, temperature and precipitation, other crops might be better suited to cultivation in the region albeit with a significant change in agricultural infrastructure. (For purposes of example, both problems are considered 'serious'.) However, because of uncertainties about RCMs (or other information) for the latter area, and given that limited funds are available, where should funds be provided for climate adaptation or human development aid projects over and above what is needed for long-term informational needs? As a matter of national priority, should funding be provided only or primarily where empirical data are more certain, e.g. regions of saltwater intrusion? Or, should funds also be provided in agricultural areas where data are less reliable but, wherein, there is a compelling need to mitigate the problems of the area? To some extent, this situation is dealt with by the UNFCCC adaptation fund requirements that defer to countries' national adaptation strategies for recommendations. Still, the fundamental questions about whether, and on what grounds, to channel resources into local and regional areas where more certain information exists remain.

A third dilemma stems from uncertainties that might require as a matter of policy that climate change adap- 
tation and human development aid funds be provided to places where more certain information exists. Doing so could create conflicts with the precautionary principle, which more or less states that 'uncertainty should not be used to delay actions to protect environmental and human health' (Kriebel et al. 2001). In other words, much of the precautionary principle and its rationale is based on the fact that if policy and decision-makers wait until more certain information becomes available, prevailing problems will only become worse and, therefore, it is better to make decisions based on social and environmental 'indicators' as opposed to scientific knowledge about which there is a higher degree of confidence (Lemons 1996).

The uncertainties mentioned so far not only make it difficult to plan climate change adaptation and human development aid with a high degree of confidence and efficiency, but also create ethical problems in need of clarification and resolution. The longer we wait for more certain information the more programs designed to alleviate poverty and improve human welfare are delayed, and the longer we wait for efficacious action on global climate change the more the risks imposed on the poor will increase; on the other hand, if development programs are initiated without regard to reasonably certain future climate conditions, they risk failing. Interestingly, of the 18 Millennium Development goals spread across 10 regions of the world, halfway through the program (due to end in 2015), 104 out of 180 goals either had achieved no progress or deteriorated or progress was insufficient to reach the goals if prevailing trends continue (UN 2008). It is hard to imagine that, as the impacts of climate change become more manifest, progress on the Millennium Development's goals will do anything but decline.

The issue of how to handle uncertainty about the local and regional impacts of global climate change are complicated because, as mentioned above, there is a tension created by waiting for more and better scientific information and therefore delaying actions that potentially could more immediately mitigate impacts and improve human welfare. Further, there is no agreement upon international procedure for how to handle uncertainties, i.e. whether it is better to delay actions until more information becomes available or take more immediate actions despite the uncertainties. Consequently, how to handle uncertainties extends far beyond mere recommendations to improve scientific capabilities. Given that the UNFCCC and most human development aid organizations rely on GCMs and given that such models as well as state-of-the-art RCMs are not sufficient to provide highly temporal or spatial data (including predictive), there is need for more study on how to handle uncertainties in a way that allows for protection of the most vulnerable populations.

\section{CONFLICTS BETWEEN CLIMATE CHANGE ADAPTATION, DEVELOPMENT AID, AND NON-HUMAN SPECIES}

The IPCC's AR4 report projects that 20 to $30 \%$ of the world's species could become extinct by the end of this century due to global climate change (IPCC 2007). Generally speaking, most ethical considerations of global climate change and even more so human development aid focus on human suffering but discount the impacts on the world's biota, except insofar as a known benefit to human wellfare is established (WB 2009). It could be argued that invoking concern about nonhuman species is not necessary in some aspects of climate change science and policy, e.g. atmospheric stabilization values of greenhouse gases can be focused on impacts on humans without invoking concern about non-human species because stabilization values that protect humans will, for the most part, protect nonhuman species as well. Beyond this one point, other considerations suggest that if the world does not take urgent action to mitigate global climate change, conflicts between protection of non-human species and achieving the goals of human development aid will increase, both because of increased threats to the ecosystem services provided by the world's biota, upon which humans depend, and also because of intrinsic reasons to preserve species in the light of mass extinctions projected by the IPCC.

Numerous recommendations have been made to try to reduce conflicts between humans and non-human species in a recent US Fish and Wildlife Service report (USFWS 2009). Protection of the polar bear by agencies in the USA is one example. Basically, by giving the polar bear a protected status as a species endangered due to global climate change, the recommendations for protection consist of trying to ensure that development activities within the polar bear habitat do not exacerbate stresses imposed by climate change. These recommendations have bearing not only on energy and mineral companies utilizing polar regions, but also on indigenous peoples where negotiations are underway to have them reduce their take of polar bears through hunting. Another example is from the Indian state Gujarat, where a semi-arid region suffering from climate change-induced drought had been set aside as a protected preserve (Gir National Park and Sanctuary) for Asian lions, mostly by relocating and excluding people from the area, including many whose families have lived for centuries within what is now the preserve (Chauhan 2003). Obviously, both the relocation and the exclusion of people from the protected area are controversial, as these policies are viewed as 'putting animals before people'. Complicating the issue is that the outskirts of the protected area, where 
most people have been relocated to, has been impacted by drought conditions resulting in people moving back into the protected area, thereby increasing conflicts between humans and other species, including the Asian lion.

Neither the example of protection of polar bears nor the Asian lion in Gujarat is without conflicts of interests between those favoring human interests and those favoring adequate protection of non-human species given the grave threats imposed by global climate change on a large number of species. The recent USFWS (2009) report concluded that despite whatever other actions might be taken, one of the things that must be done to protect species from global climate change is to reduce the impacts on species from humans with respect to the taking of sensitive species and in changing species' habitats. Yet, reports such as this do not provide clear prescriptions on how to reduce conflicts between human and non-human species' needs. How should the climate change and development communities address such a problem?

Recently, Sukhdev (2009) from the World Bank proposed that the way to reduce conflicts between humans and non-humans, insofar as global climate change and human development aid are concerned, is to place a monetary value on ecosystem and species' services to humans. Yet, this kind of proposal is fraught with difficulties and built-in bias toward human interests (Lemons 1995). For example, if there are uncertainties about the value of a particular species to humans, even though, in fact, the species might have significant direct or indirect value for humans, the value gets significantly discounted in economic analysis. Further, ecologists know little of the roles and importance of most species to ecological integrity and maintenance of other species and again, given this uncertainty, such species get discounted in economic analysis. In contrast to these kinds of proposals, others have focused on practical matters and have concluded that conservation of non-human species needs to be considered outside of the context of human needs for the simple reason that if human needs are the issue, most conservation programs for non-human species will fail (Livingston 2007). Then, too, is the argument that non-human species have intrinsic rights to existence and these should not be ignored in trying to make the earth home for both humans and non-humans (Rolston 1994). Simply put, if projections from the IPCC and other conservation biology organizations are that global climate change might result in the extinction of 20 to $30 \%$ of all species, the magnitude of this problem can no longer be avoided by those concerned with global climate change adaptation or human development aid, especially the latter.

\section{CONCLUSION}

The uncertainties about the impacts of global climate change at local and regional levels raise unresolved questions about their relation to human development aid: whether, given these uncertainties about global climate change, adaptation and local and regional levels of human development aid programs should continue as planned? How should we try to take into account the uncertainties inherent in projecting impacts of local and regional climate change? For example, proceed on the basis of a 'best guess estimate' or wait until more uncertainties are resolved? Further, given the projections that from 20 to $30 \%$ of the world's species might become extinct due to global climate change, considerations of the protection of non-human species and the conflicts with anthropocentric goals can no longer be avoided.

\section{LITERATURE CITED}

Allison I, Bindoff NL, Bindschadler RA, Cox PM and others (2009) The Copenhagen diagnosis: updating the world on the latest climate. The University of New South Wales Climate Change Research Centre, Sydney. Available at www.ccrc.unsw.edu.au/Copenhagen/Copenhagen_Diagnosis_LOW.pdf (accessed 18 July 2010)

Brown DA (2010) Integrating development and climate change ethics. Conference, 14-16 April 2010, Penn State University, College Station, PA. Available at http://rockethics.psu.edu/climate/events/idcce/index.shtml (accessed 16 June 2010)

Chauhan M (2003) Conserving biodiversity in arid regions: experiences with protected areas in India. In: Lemons J, Victor R, Schaeffer D (eds) Conserving biodiversity in arid regions. Kluwer Academic Publishers, Dordrecht, p 231-248

Georgi F, Jones C (2009) Regional climate modeling. Workshop on evaluating and improving regional climate projections, 11-13 February 2009, Toulouse. Available at www.clivar.org/organization/wg cm/regional.php\#using (accessed 18 November 2009)

IPCC (Intergovernmental Panel on Climate Change) (2007) Climate Change 2007. IPCC fourth assessment report (AR4). IPCC, Geneve. Available at www.ipcc.ch/ (accessed 27 October 2009)

Kriebel D, Tickner J, Epstein P, Lemons J and others (2001) The precautionary principle in environmental science. Environ Health Perspect 109:871-876

Kueppers LM, Baer P, Harte J, Haya B, Koteen LE, Smith ME (2004) A decision matrix approach to evaluating the impacts of land-use undertaken to mitigate climate change. Clim Change 63:247-257

Kueppers LM, Snyder MA, Sloan LC, Zavaleta ES, Fulfrost B (2005) Modeled regional climate changes and California endemic oak ranges. Proc Natl Acad Sci USA 102: 16281-16286

Lemons J (1995) Conservation of biodiversity and sustainable development. In: Lemons J, Brown DA (eds) Sustainable development: science, ethics, and public policy. Kluwer Academic Publishers, Dordrecht, p 77-109

Lemons J (ed) (1996) Scientific uncertainty and environmental problem solving. Blackwell Science, Cambridge, MA 
Livingston JA (2007) The John A. Livingston reader: the fallacy of wildlife conservation and one cosmic instant. A natural history of human arrogance. McClelland \& Stewart, Toronto

Michaelowa A, Michaelowa K (2010) Coding error or statistical embellishment? The political economy of reporting climate aid. Center for Comparative and International Studies, University of Zurich. Available at www.cis.ethz.ch/ publications/publications/2010_WP56_Michaelowa_Mich aelowa.pdf (accessed 24 June 2010)

Pierce DW, Barnett TP, Santer BD, Gleckler PJ (2009) Selecting global climate models for regional climate change studies. Proc Natl Acad Sci USA 106:8441-8446

Rolston III Holmes (1994) Conserving natural value. Columbia University Press, New York, NY

Sukhdev P (ed) (2009) The economics of ecosystems and biodiversity. TEEB, United Nations Environment Programme, New York, NY

Tschakert P (2007) Views from the vulnerable: perceptions on climate and other stressors in the Sahel. Glob Environ Change 17:381-396

UN (United Nations) (2008) Millennium development goals: 2008 progress chart. Statistics Division, Department of Economic and Social Affairs, UN, New York, NY

Editorial responsibility: Darryl Macer, Bangkok, Thailand
UNDP (United Nations Developent Programme) (2007) Human development report 2007/2008. Fighting climate change: human solidarity in a divided world. UNDP, New York, NY. Available at http://hdr.undp.org/en/media/ HDR_20072008_EN_Complete.pdf (accessed 24 June 2010)

USFWS (US Fish and Wildlife Service) (2009) Rising to the challenge: strategic plan for responding to accelerating climate change. US Fish and Wildlife Service, Washington, DC

WB (World Bank) (2009) World development report 2010: development and climate change. The World Bank, Washington, DC

WCRP (World Climate Research Programme) (2009) Workshop on evaluating and improving regional climate projections, 11-13 February 2009, Toulouse. Available at www.clivar.org/organization/wg cm/regional.php\#using (accessed 18 November 2009)

UNESCO (United Nations Educational, Scientific and Cultural Organisation) (2000) Science for the twenty-first century, a new commitment. World Conference on Science, June 1999, Budapest. UNESCO, Paris. Available at http:// unesdoc.unesco.org/images/00120012/001207/120706e.pdf (accessed 3 September 2010)

Submitted: March 12, 2010; Accepted: July 25, 2010 Proofs received from author(s): October 8, 2010 